exploited. For example, it will be necessary to develop better means to identify these cells with specific markers; to improve understanding of the mechanisms that induce these cells, either naturally or during therapy; to enhance understanding of the mechanism(s) of suppression; and to improve insight into the signaling events that underlie the selective induction of Hsp60 in intermediate-avidity CD4 ${ }^{+} \mathrm{T}$ cells. It will also be important to better define the role of CD94/NKG2A, the receptor on NK cells and a subset of $C D 8^{+} \mathrm{T}$ cells that is inhibited by Qa-1/Qdm or HLA-E/B7sp complexes (20), in conferring self/nonself tolerance. Other outstanding questions are whether Qa-1/HLA-E-restricted CD8 ${ }^{+}$ Tregs represent a separate lineage of $\mathrm{T}$ lymphocytes and whether HLA-E polymorphisms are associated with human disease, as has been suggested for T1D (24). Finally, it will be important to determine how these cells impact immune responses during different immunological situations such as infection, allograft rejection, cancer, and allergies. With more studies like those performed by Jiang and colleagues (5), answers to many of these questions should be within reach, bringing us closer to attaining the holy grail of immunology.

\section{Acknowledgments}

The author is funded by the NIH.
Address correspondence to: Luc Van Kaer, Department of Microbiology and Immunology, Vanderbilt University School of Medicine, Medical Center North, Room A-5301, Nashville, Tennessee 37232, USA. Phone: 615.343.2707; Fax: 615.343.2972; E-mail: luc.van.kaer@vanderbilt.edu.

1. Billingham RE, Brent L, Medawar PB. Actively acquired tolerance of foreign cells. Nature. 1953; 172(4379):603-606

2. Starr TK, Jameson SC, Hogquist KA. Positive and negative selection of T cells. Annu Rev Immunol. 2003;21:139-176.

3. Mueller DL. Mechanisms maintaining peripheral tolerance. Nat Immunol. 2010;11(1):21-27.

4. Jiang H, Chess L. Regulation of immune responses by T cells. New Engl J Med. 2006;354(11):1166-1176.

5. Jiang $\mathrm{H}$, et al. HLA-E-restricted regulatory $\mathrm{CD}^{+}$ $\mathrm{T}$ cells are involved in development and control of human autoimmune type 1 diabetes. J Clin Invest. 2010;120(10):3641-3650.

6. Gershon RK, Kondo K. Cell interactions in the induction of tolerance: the role of thymic lymphocytes. Immunology. 1970;18(5):723-737.

7. Shevach EM. Regulatory T cells in autoimmmunity. Annu Rev Immunol. 2000;18:423-449.

8. Jiang $H$, Chess $L$. The specific regulation of immune responses by $\mathrm{CD}^{+} \mathrm{T}$ cells restricted by the MHC class Ib molecule, Qa-1. Annu Rev Immunol. 2000; 18:185-216.

9. Smith TR, Kumar V. Revival of $\mathrm{CD}^{+}$Treg-mediated suppression. Trends Immunol. 2008;29(7):337-342.

10. Sarantopoulos S, Lu L, Cantor H. Qa-1 restriction of $\mathrm{CD}^{+}$suppressor T cells. J Clin Invest. 2004; 114(9):1218-1221.

11. Sun D, Qin Y, Chluba J, Epplen JT, Wekerle H. Suppression of experimentally induced autoimmune encephalomyelitis by cytolytic T-T cell interactions. Nature. 1988;332(6167):843-845.

12. Jiang $H$, et al. T cell vaccination induces $\mathrm{T}$ cell recep- tor V $\beta$-specific Qa-1-restricted regulatory $\mathrm{CD}^{+} \mathrm{T}$ cells. Proc Natl Acad Sci US A. 1998;95(8):4533-4537.

13. Jiang $\mathrm{H}$, Zhang SI, Pernis B. Role of $\mathrm{CD}^{+} \mathrm{T}$ cells in murine experimental allergic encephalomyelitis. Science. 1992;256(5060):1213-1215.

14. Koh DR, Fung-Leung WP, Ho A, Gray D, AchaOrbea H, Mak TW. Less mortality but more relapses in experimental allergic encephalomyelitis in CD8-/- mice. Science. 1992;256(5060):1210-1213.

15. Lu L, Cantor H. Generation and regulation of $\mathrm{CD}^{+}$regulatory T cells. Cell Mol Immunol. 2008; 5(6):401-406

16. Tennakoon DK, Mehta RS, Ortega SB, Bhoj V, Racke MK, Karandikar NJ. Therapeutic induction of regulatory, cytotoxic $\mathrm{CD}^{+} \mathrm{T}$ cells in multiple sclerosis. J Immunol. 2006;176(11):7119-7129.

17. Brimnes J, Allez M, Dotan I, Shao L, Nakazawa A, Mayer L. Defects in CD8 ${ }^{+}$regulatory T cells in the lamina propria of patients with inflammatory bowel disease. J Immunol. 2005;174(9):5814-5822.

18. Cantor $\mathrm{H}$, et al. Immunoregulatory circuits among T-cell sets. Identification of a subpopulation of T-helper cells that induces feedback inhibition. J Exp Med. 1978;148(4):871-877.

19. Rodgers JR, Cook RG. MHC class Ib molecules bridge innate and acquired immunity. Nat Rev Immunol. 2005;5(6):459-471.

20. Jensen PE, Sullivan BA, Reed-Loisel LM, Weber DA Qa-1, a nonclassical class I histocompatibility molecule with roles in innate and adaptive immunity. Immunol Res. 2004;29(1-3):81-92.

21. Hu D, Ikizawa K, Lu L, Sanchirico ME, Shinohara ML, Cantor H. Analysis of regulatory CD8 T cells in Qa-1deficient mice. Nat Immunol. 2004;5(5):516-523.

22. Jiang H, et al. An affinity/avidity model of peripheral T cell regulation. J Clin Invest. 2005;115(2):302-312.

23. Chen W, et al. Perceiving the avidity of T cell activation can be translated into peripheral $\mathrm{T}$ cell regulation. Proc Natl Acad Sci US A. 2007;104(51):20472-20477.

24. Hodgkinson AD, Millward BA, Demaine AG. The HLA-E locus is associated with age at onset and susceptibility to type 1 diabetes mellitus. Hum Immunol. 2000;61(3):290-295

\title{
Location, location, regulation: a novel role for $\beta$-spectrin in the heart
}

\author{
Kevin J. Sampson and Robert S. Kass
}

Department of Pharmacology, College of Physicians and Surgeons, Columbia University, New York, New York, USA.

\begin{abstract}
Voltage-gated $\mathrm{Na}^{+}$channels (VGSCs) are responsible for the rising phase of the action potential in excitable cells, including neurons and skeletal and cardiac myocytes. Small alterations in gating properties can lead to severe changes in cellular excitability, as evidenced by the plethora of heritable conditions attributed to mutations in VGSCs highlighting the need to better understand VGSC regulation. In this issue of the JCI, Hund et al. identify the ability of a key structural protein, $\beta_{\mathrm{IV}}$-spectrin, to bind and recruit $\mathrm{Ca}^{2+} /$ calmodulin kinase II to the channel at a cellular location key to successful action potential initiation and propagation, where it can mediate function and excitability.
\end{abstract}

Conflict of interest: The authors have declared that no conflict of interest exists.

Citation for this article: $J$ Clin Invest. 2010;120(10):3434-3437. doi:10.1172/JCI44810.

\section{The $\mathrm{Na}^{+}$channel and disease}

In excitable tissues, such as muscle, heart, and nerve, action potential (AP) initiation is most often accomplished by the opening of voltage-gated $\mathrm{Na}^{+}$channels (VGSCs). VGSC activity is critical for normal impulse conduction and contributes to control of the duration and morphology of the cellular AP. VGSCs have a primary pore-forming $\alpha$ subunit that is a protein with 4 homologous domains, each with 6 transmembrane segments (Figure 1).

Inward $\mathrm{Na}^{+}$current is typically the largest membrane current in excitable cells and must quickly inactivate to allow the cell to begin to repolarize. In myocytes, $\mathrm{Na}_{v} 1.5$ (which is encoded by $S C N 5 A$ ) is the principal VGSC $\alpha$ subunit expressed. It is predominantly localized in the inter- 


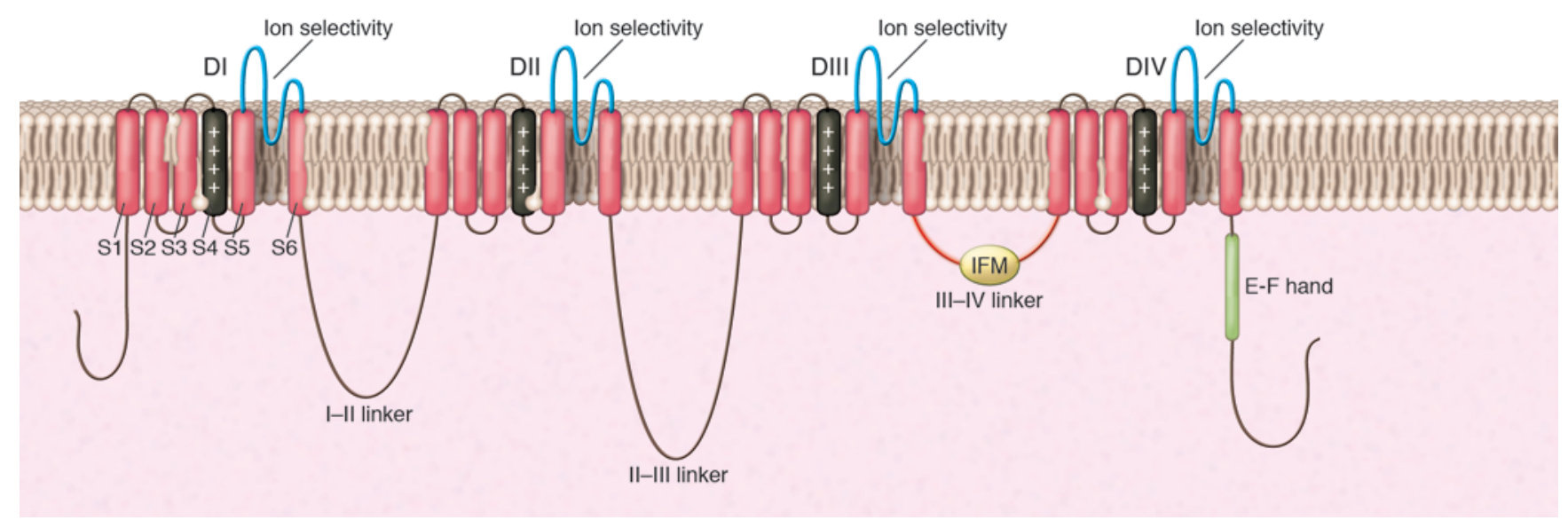

\section{Figure 1}

The $\alpha$ subunit of the cardiac $\mathrm{Na}^{+}$channel. DI-DIV denotes the 4 homologous domains of the $\alpha$ subunit; S1-S6 denote the 6 transmembrane segments. S5 and S6 are the pore-lining segments, and the S4 helices (black) serve as voltage sensors. In the connecting loop between DIII and DIV, the 3 residues isoleucine, phenylalanine, and methionine (IFM) are known to play a key role in the fast inactivation process.

calated discs in order to contribute to successful propagation of APs and the normal sequence of excitation-contraction (Figure 2A). Pivotal and key roles of VGSC activity in human physiology have been highlighted by the discovery of inherited mutations in $\mathrm{Na}^{+}$channel $\alpha$ subunit-encoding genes linked to numerous disease phenotypes in multiple systems. Examples include epilepsy, linked to $\mathrm{Na}_{v} 1.1$; periodic paralysis, linked to $\mathrm{Na}_{v} 1.4$; cardiac conduction disease, linked to $\mathrm{Na}_{\mathrm{v}} 1.5$; and long QT syndrome, linked to $\mathrm{Na}_{\mathrm{v}} 1.5$ (1-3). In cardiac tissue, loss of function of $\mathrm{Na}_{\mathrm{v}} 1.5$ channels can lead to cardiac conduction disease and Brugada syndrome, whereas mutations that disrupt or delay inactivation, allowing for more $\mathrm{Na}^{+}$current at later phases of the AP, lead to long QT syndrome (2).

Most VGSCs activate and inactivate completely within the first few milliseconds of the AP, thus very quickly reducing or eliminating their contribution to AP waveform. When VGSCs fail to inactivate normally, the resulting late (i.e., not inactivated) $\mathrm{Na}^{+}$current provides a substantial inward current that prolongs AP duration (APD) and can lead to arrhythmia, either directly through the altered AP waveform or indirectly via altered intracellular $\mathrm{Na}^{+}$concentrations. In recent years, a great deal of effort has been put into understanding the role of this late $\mathrm{Na}^{+}$current and the therapeutic benefits of its blockade (4). Late $\mathrm{Na}^{+}$current is preferentially blocked by a large number of drugs that interact with the pore-forming region of the $\alpha$ subunit at a well-described site that is bound by several local anesthetic drug molecules (5-7). In addition to a role in heritable disease (including long QT and epilepsy), emerging evidence has revealed that aberrant late $\mathrm{Na}^{+}$current may play a role in the advanced stages of heart failure (8). Therefore, understanding not only the structures within the VGSC $\alpha$ subunit, but also the molecular identity of partner proteins that modify $\mathrm{Na}^{+}$channel function is critical to the understanding of a number of complex disease phenotypes.

\section{The $\mathrm{Na}^{+}$channel as a macromolecular complex}

Our understanding of ion channels as macromolecular complexes that tightly control channel function and regulation has grown in recent years (9). For example, in a number of PKA-sensitive ion channel complexes, the primary pore-containing subunit is in complex with an A kinase-anchoring protein (AKAP) that recruits kinase, phosphatases, and phosphodiesterases to control the local phosphorylation state (10).

VGSCs also form macromolecular complexes with the $\alpha$ subunit, having been shown to interact with numerous proteins, including a $\beta$ subunit, ankyrin, syntrophin, dystrophin, fibroblast growth factor homologous factor 1B, calmodulin, and Nedd4-like ubiquitin-protein ligases (Figure 2B), all of which are involved in the regulation of channel activity, correct cellular localization, and biosynthesis and degradation of the $\alpha$ subunit $(11,12)$. Mutations in a number of these interacting proteins have been associated with inherited disease, including variants 4 , 10 , and 12 of long QT syndrome $(13,14)$.
Another protein shown to regulate VGSCs primarily in - but not limited to - cardiac muscle, including an effect on late $\mathrm{Na}^{+}$current, is $\mathrm{Ca}^{2+} /$ calmodulin kinase II (CaMKII; refs. 15,16$)$. In addition to having an effect on VGSC current, CaMKII has been shown to be upregulated in heart failure and may therefore be a therapeutic target $(17,18)$. In this issue of the JCI, Hund et al. use sequence analysis to identify $\beta_{\mathrm{IV}}$-spectrin as a CaMKII binding protein that participates in the $\mathrm{Na}_{\mathrm{v}} 1.5$ macromolecular complex in cardiac myocyte intercalated discs (ref. 19 and Figure $2 \mathrm{~B}$ ). Therefore, $\beta_{\mathrm{IV}}$-spectrin appears analogous to the more ubiquitous AKAPs in that it recruits a kinase to a local signaling environment involving an ion channel. Moreover, Hund et al. found that $\beta_{\mathrm{IV}}$-spectrin was required for the action of CaMKII on $\mathrm{Na}_{v} 1.5$ (19). In mouse cardiomyocytes, abolishing CaMKII activity via a mutation in $\beta_{\mathrm{IV}}$-spectrin positively shifted baseline $\mathrm{Na}^{+}$channel steady-state inactivation (SSI) and eliminated the late $\mathrm{Na}^{+}$ current and SSI shift normally induced by $\beta$-adrenergic receptor stimulation by isoproterenol. Hund and colleagues further demonstrated that this was caused by $\beta_{\mathrm{IV}^{-}}$ spectrin directly regulating CaMKII-mediated phosphorylation of a specific serine residue in the $\mathrm{Na}_{v} 1.5 \mathrm{I}-\mathrm{II}$ linker, S571. Consistent with the present understanding of the functional role of $\mathrm{Na}^{+}$channel activity in the heart, the hyperpolarizing shift in SSI observed in mice expressing mutant forms of $\beta_{\mathrm{IV}}$-spectrin led to reduced excitability, and the decrease in late current resulted in shortened APD and a subsequent decrease 
A

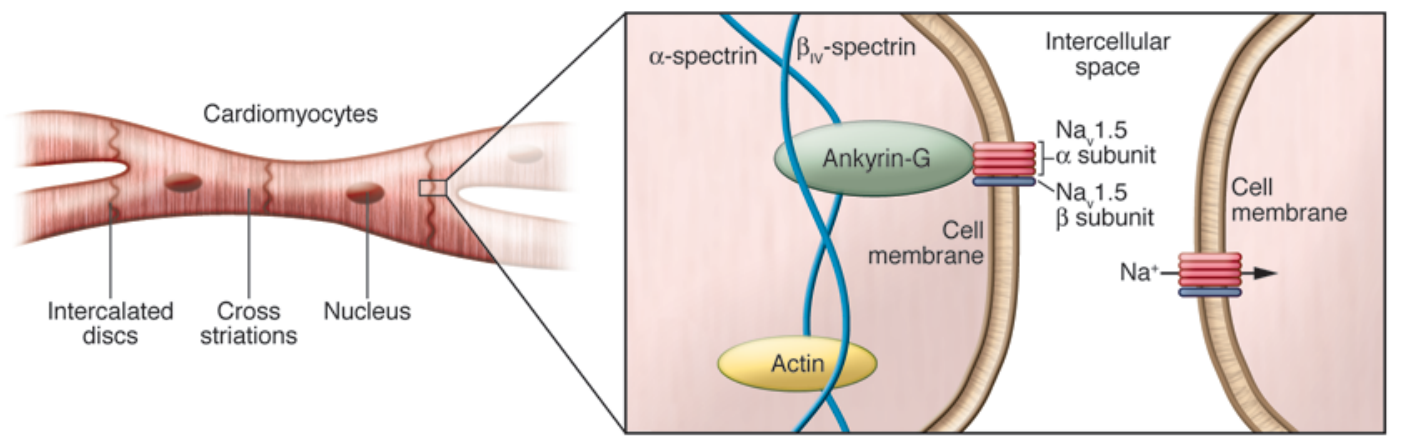

B

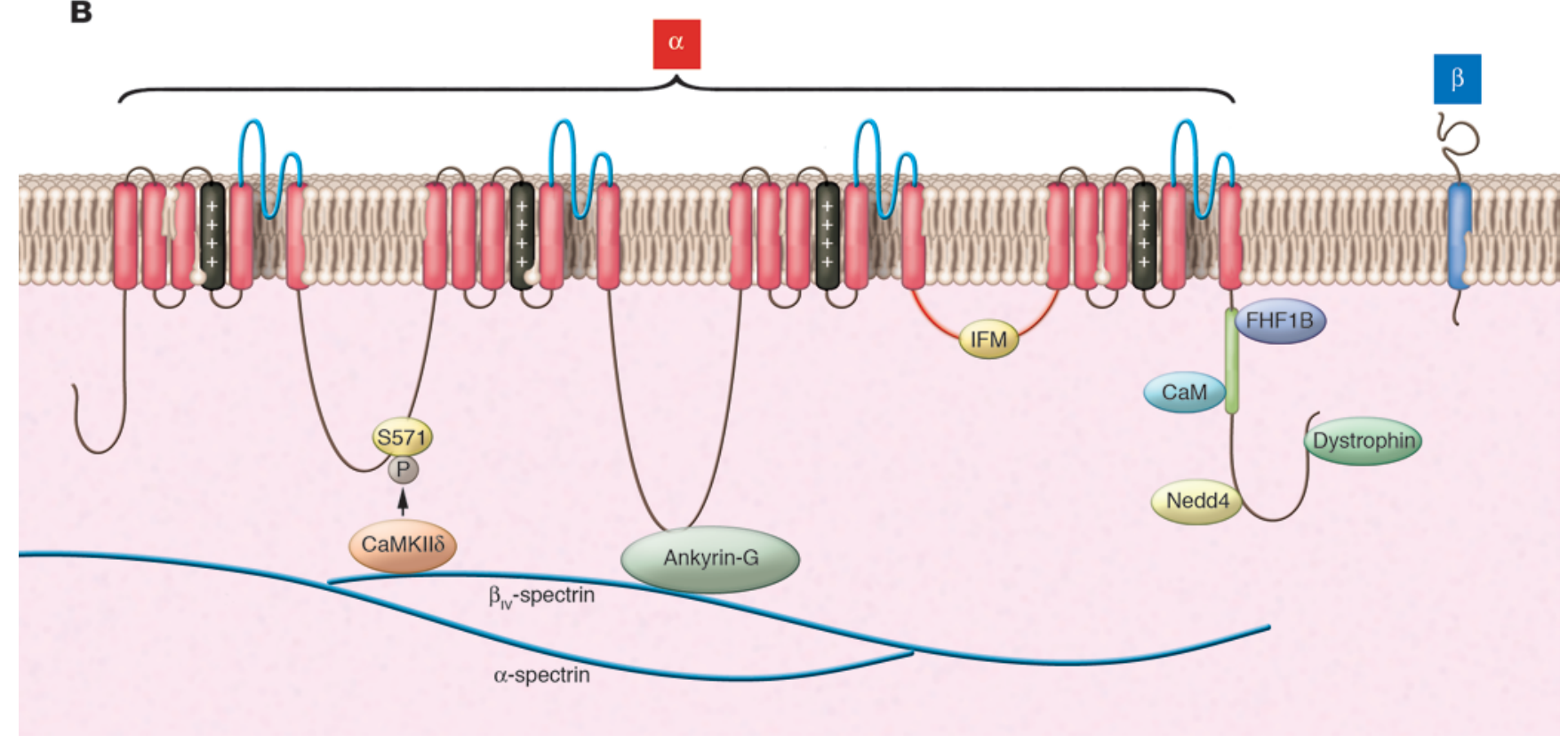

Figure 2

The macromolecular complex associated with the VGSC Na 1.5 in cardiac myocytes. (A) Ankyrin-G brings the VGSC in complex with the actinspectrin cytoskeleton at the cardiac intercalated discs, where they can participate in initiation and propagation of the cardiac AP. (B) In this issue of the $\mathrm{JCl}$, Hund et al. show that $\beta_{\mathrm{IV}}$-spectrin recruits CaMKII $\delta$ to the Nav 1.5 -ankyrin complex and that CaMKII $\delta$ then modulates function via phosphorylation of a serine in the I-II linker (19). Binding sites for a number of interacting proteins are also shown. CaM, calmodulin; FHF1B, fibroblast growth factor homologous factor 1B; Nedd4, Nedd4-like ubiquitin-protein ligases.

in QT interval. The finding of Hund et al. that $\beta_{\mathrm{IV}}$-spectrin associated with CaMKII in cerebellar Purkinje neurons targeting it to the axonal initial segments - critical regions for the generation of APs in which VGSCs localize - suggests that the key modulatory roles of $\beta_{\mathrm{IV}}$-spectrin may very well exist in the brain, and perhaps other tissues, in addition to the heart.

\section{Conclusions and perspective}

There has been increasing understanding that ion channels do not exist on cell membranes simply as pore-forming proteins, but are instead in complex with a host of proteins that can influence the channel in a multitude of ways, including aiding channel targeting to specific subcellular regions, controlling the phosphorylation state of the channel, participating in biosynthesis and degradation of the channel, and altering channel gating allosterically. The present study by Hund et al. increases our understanding of the molecular identity of the complex controlling the phosphorylation state of the predominant cardiac VSGC (19). As phosphorylation of the channel affects channel-gating properties (i.e., SSI and late $\mathrm{Na}^{+}$current), and small perturbations in these properties are linked to disease in a number of systems, understanding the molecular components in this pathway represents a significant contribution to the field. Subsequently, this molecular pathway may represent a novel therapeutic target or serve as a new locus for heritable channelopathies. Furthermore, the ability of $\beta_{\mathrm{IV}}$-spectrin to recruit CaMKII to distinct subcellular compartments critical to cellular excitability in other cell types may indicate a broader role within the cell, as it can serve not only as a structural protein, but also in the regulation of posttranslational states of membrane proteins.

\section{Acknowledgments}

The authors' work is supported by National Heart, Lung, and Blood Institute, NIH, grant 2R01 HL 044365-18.

Address correspondence to: Robert S. Kass, Department of Pharmacology, Columbia University Medical Center, 630 W. 168th 
St., New York, New York 10032, USA. Phone: 212.305.3720; Fax: 212.305.3545; E-mail: rsk20@columbia.edu.

1. Fischer TZ, Waxman SG. Familial pain syndromes from mutations of the NaV1.7 sodium channel. Ann N Y Acad Sci. 2010;1184:196-207.

2. Ruan Y, Liu N, Priori SG. Sodium channel mutations and arrhythmias. Nat Rev Cardiol. 2009; 6(5):337-348.

3. Catterall WA, Dib-Hajj S, Meisler MH, Pietrobon D. Inherited neuronal ion channelopathies: new windows on complex neurological diseases. J Neurosci. 2008;28(46):11768-11777.

4. Belardinelli L, Shryock JC, Fraser H. Inhibition of the late sodium current as a potential cardioprotective principle: effects of the late sodium current inhibitor ranolazine. Heart. 2006;92(suppl 4):iv6-iv14.

5. Fozzard HA, Lee PJ, Lipkind GM. Mechanism of local anesthetic drug action on voltage-gated sodium channels. Curr Pharm Des. 2005;11(21):2671-2686.

6. Bankston JR, Kass RS. Molecular determinants of local anesthetic action of beta-blocking drugs: Implications for therapeutic management of long QT syndrome variant 3. J Mol Cell Cardiol. 2010;48(1):246-253.

7. Fredj S, Sampson KJ, Liu H, Kass RS. Molecular basis of ranolazine block of LQT-3 mutant sodium channels: evidence for site of action. BrJ Pharmacol. 2006;148(1):16-24

8. Undrovinas A, Maltsev VA. Late sodium current is a new therapeutic target to improve contractility and rhythm in failing heart. Cardiovasc Hematol Agents Med Chem. 2008;6(4):348-359.

9. Sampson KJ, Kass RS. Molecular mechanisms of adrenergic stimulation in the heart. Heart Rhythm. 2010;7(8):1151-1153.

10. Carnegie GK, Means CK, Scott JD. A-kinase anchoring proteins: from protein complexes to physiology and disease. IUBMB Life. 2009;61(4):394-406.

11. Abriel H, Kass RS. Regulation of the voltage-gated cardiac sodium channel Nav1.5 by interacting proteins. Trends Cardiovasc Med. 2005;15(1):35-40.

12. Abriel H. Cardiac sodium channel $\mathrm{Na}(\mathrm{v}) 1.5$ and interacting proteins: Physiology and pathophysi- ology. J Mol Cell Cardiol. 2010;48(1):2-11.

13. Hedley PL, et al. The genetic basis of long QT and short QT syndromes: a mutation update. Hum Mutat. 2009;30(11):1486-1511.

14. Hedley PL, et al. The genetic basis of Brugada syndrome: a mutation update. Hum Mutat. 2009; 30(9):1256-1266

15. Maltsev VA, ReznikovV, Undrovinas NA, Sabbah HN, Undrovinas A. Modulation of late sodium current by $\mathrm{Ca} 2+$, calmodulin, and CaMKII in normal and failing dog cardiomyocytes: similarities and differences. AmJ Physiol Heart Circ Physiol. 2008;294(4):H1597-H1608.

16. Wagner S, et al. Ca2+/calmodulin-dependent protein kinase II regulates cardiac $\mathrm{Na}+$ channels. JClin Invest. 2006;116(12):3127-3138.

17. Maier LS, Bers DM. Calcium, calmodulin, and calcium-calmodulin kinase II: heartbeat to heartbeat and beyond. J Mol Cell Cardiol. 2002;34(8):919-939.

18. Maier LS. Role of CaMKII for signaling and regulation in the heart. Front Biosci. 2009;14:486-496.

19. Hund TJ, et al. A $\beta_{\mathrm{IV}}$-spectrin/CaMKII signaling complex is essential for membrane excitability in mice. J Clin Invest. 2010;120(10):3508-3519.

\title{
In obesity and weight loss, all roads lead to the mighty macrophage
}

\author{
Alex Red Eagle ${ }^{1}$ and Ajay Chawla ${ }^{2,3}$
}

1Department of Genetics and 2Division of Endocrinology, Metabolism, and Gerontology, Department of Medicine, ${ }^{3}$ Graduate Program in Immunology, Stanford University School of Medicine, Stanford, California, USA.

\begin{abstract}
Obesity is associated with infiltration of white adipose tissue (WAT) by macrophages, which contributes to the development of insulin resistance. In this issue of the JCI, Kosteli and colleagues demonstrate that weight loss is unexpectedly also associated with rapid, albeit transient, recruitment of macrophages to WAT and that this appears to be related to lipolysis.
\end{abstract}

Macrophages are derived from monocytes and comprise a heterogenous population of cells found in nearly all tissues (1). In addition to their pivotal role in host defense, inflammation, and tissue repair, studies over the last decade have focused on their role in chronic metabolic diseases, such as obesity and insulin resistance (2). The initial descriptions of macrophage infiltration of white adipose tissue (WAT) during obesity, which were published in the JCI in 2003 $(3,4)$, garnered a great deal of attention, as evidenced by over 1,000 subsequent reports that confirmed the link between adipose tissue macrophages (ATMs) and inflammation and insulin resistance. In contrast, the role of innate and adaptive immunity in weight loss, the ultimate translational

Conflict of interest: The authors declare that no conflict of interest exists.

Citation for this article: J Clin Invest. 2010; 120(10):3437-3440. doi:10.1172/JCI44721. goal of research on obesity, is less clear. In this issue of the JCI, Kosteli and colleagues report that acute weight loss results in recruitment of macrophages to WAT (5). However, in this case, the recruited macrophages do not promote inflammation but rather regulate lipolysis. Since stimuli that enhance adipocyte lipolysis increase macrophage recruitment to WAT, the authors suggest that release of FFAs is a general signal for macrophage recruitment.

\section{Obesity, inflammation, and macrophages}

The chronic, low-grade inflammation that is characteristic of obesity has long been suspected to contribute to the development of insulin resistance (6). Almost two decades ago, Spiegelman and colleagues demonstrated that TNF- $\alpha$, which is induced in the adipose tissue of obese animals, inhibits glucose disposal by promoting insulin resistance in peripheral tissues
(7). Although adipocytes were identified as the source of TNF- $\alpha$, expression of TNF- $\alpha$ was also observed in the stromovascular fraction rich in immune cells. This observation fueled a new direction in metabolic research and led to the discovery that macrophage infiltration of WAT is responsible for obesity-associated inflammation $(3,4)$.

While WAT from lean animals contains a resident population of alternatively activated macrophages (also known as M2 macrophages), which are characterized by expression of F4/80, CD301, and arginase 1 (Arg1), obesity is associated with recruitment of classically activated macrophages (also known as M1 macrophages), which are characterized by expression of F4/80, CD11c, and iNOS (Table 1). This observation led Lumeng and colleagues to conclude that obesity induces a switch in macrophage activation in WAT (8). Since alternatively activated macrophages can suppress inflammation in an autocrine and/or paracrine manner, in part via secretion of IL-10, the net effect of this shift in macrophage polarization is an increase in adipose tissue inflammation. However, this is likely to be an oversimplification because macrophages in vivo exhibit a 